\title{
Haploinsufficiency of BMP4 and OTX2 in the Foetus with an abnormal facial profile detected in the first trimester of pregnancy
}

\author{
Pavlina Capkova ${ }^{1 *} \mathbb{D}$, Alena Santava ${ }^{1}$, Ivana Markova ${ }^{2}$, Andrea Stefekova', Josef Srovnal ${ }^{3}$, Katerina Staffova ${ }^{3}$ \\ and Veronika Durdová ${ }^{2}$
}

\begin{abstract}
Background: Interstitial microdeletion $14 \mathrm{q} 22 \mathrm{q} 23$ is a rare chromosomal syndrome associated with variable defects: microphthalmia/anophthalmia, pituitary anomalies, polydactyly/syndactyly of hands and feet, micrognathia/ retrognathia. The reports of the microdeletion $14 q 22 q 23$ detected in the prenatal stages are limited and the range of clinical features reveals a quite high variability.

Case presentation: We report a detection of the microdeletion 14q22.1q23.1 spanning 7,7 Mb and involving the genes BMP4 and OTX2 in the foetus by multiplex ligation-dependent probe amplification (MLPA) and verified by microarray subsequently. The pregnancy was referred to the genetic counselling for abnormal facial profile observed in the first trimester ultrasound scan and micrognathia (suspicion of Pierre Robin sequence), hypoplasia nasal bone and polydactyly in the second trimester ultrasound scan. The pregnancy was terminated on request of the parents.

Conclusion: An abnormal facial profile detected on prenatal scan can provide a clue to the presence of rare chromosomal abnormalities in the first trimester of pregnancy despite the normal result of the first trimester screening test. The patients should be provided with genetic counselling. Usage of quick and sensitive methods (MLPA, microarray) is preferable for discovering a causal aberration because some of the CNVs cannot be detected with conventional karyotyping in these cases. To the best of our knowledge, this is the earliest detection of this microdeletion (occurred de novo), the first case detected by MLPA and confirmed by microarray. Literature review of the genotype-phenotype correlation in similar reports leads us to the conclusion that dosage imbalance of the chromosomal segment 14q22q23 (especially haploinsuffiency of the genes BMP4 and OTX2) contributes significantly to orofacial abnormalities. Association of the region with the Pierre Robin sequence appears to be plausible.
\end{abstract}

Keywords: Microdeletion 14q22q23, Micrognathia, First trimester ultrasound, Pierre Robin sequence

\section{Background}

We report the detection of interstitial microdeletion $14 \mathrm{q} 22 \mathrm{q} 23$ in a foetus with an abnormal facial profile in the first trimester of gestation and micrognathia, hypoplasia of the nasal bone and polydactyly in the second trimester of gestation discovered by ultrasound. Interstitial microdeletion $14 \mathrm{q} 22 \mathrm{q} 23$ is a rare chromosomal

\footnotetext{
*Correspondence: pavlina.capkova@fnol.cz; pcapkova@seznam.cz ${ }^{1}$ Department of Medical Genetics, University Hospital Olomouc, I.P.Pavlova 6, Olomouc, Czech Republic

Full list of author information is available at the end of the article
}

syndrome associated with variable defects: microphthalmia/anophthalmia, pituitary anomalies, polydactyly/syndactyly of hands and feet, micrognathia/retrognathia. A growth restriction and developmental delay/mental retardation are common. Haploinsufficiency of the genes BMP4 (bone morphogenetic protein 4) and OTX2 (orthodenticle homeobox 2) is crucial for the majority of the phenotype features in the 14q22q23 microdeletion syndrome [1-5]. A prenatal ultrasound scan of these aberrations is less obvious and can be more difficult to distinguish or detect. In the case report, we describe the 
prenatal diagnosis of the interstitial microdeletion 14q22q23. The first marker (abnormal facial profile) was observed during the ultrasound scan in the first trimester of pregnancy and has not been described previously. We provide readers with a short review of the literature summarising clinical features of the aberration observed postnatally and prenatally. We focused on the orofacial malformations as a detectable feature for this abnormality in the early stages of pregnancy.

\section{Case presentation}

A 32-year-old pregnant woman (gravida 2, para 1) was referred to our department at 17th week of gestation for genetic counselling before amniocentesis recommended on the basis of ultrasound findings. The pregnancy was uneventful, the first trimester screening test, counting on the individual risk for trisomies $21,13,18$, was with normal results. An abnormal facial profile of the foetus was observed (mandible hypoplasia - Pierre Robin anomaly or cleft lip were suspected) on the first trimester scan. Micrognathia was subsequently confirmed during the second trimester scan (17th week of the pregnancy). Bilateral postaxial polydactyly of the hands and hypoplasia of the nasal bone were also detected (Fig. 1). Both parents were non-consanguineous, the paternal age was 30, the first child - a girl - was healthy. The family history was unremarkable except for one case of a foetal congenital heart disorder in the child of a paternal aunt.

DNA was obtained from uncultured amniotic cells. A rapid molecular DNA analysis - QFPCR - excluded trisomies of the chromosomes 21, 18, 13. Conventional Gbanding karyotyping was performed on metaphase mitotic cells obtained from amniotic fluid according to standard protocols. The karyotype of the foetus was 46,XY (500 bphs). MLPA testing with probemixes SALSA MLPA P036-E3 Subtelomeres Mix1 and P070B3 Subtelomeres Mix 2B and P245 -B1 Microdeletion Syndromes 1 (MRC, Holland) were required for quick targeted exclusion of "common" microdeletions/microduplications. The DiGeorge syndrome was also excluded with probemix P311 - A2 CHD and P250-B2 DiGeorge syndrome (MRC, Holland) because of the micrognathia and family history of congenital heart defect. MLPA tests were performed according to the manufacturer's protocols. Analysis of peak areas was performed using software Coffalyser (MRC, Holland).

The loss of the gene BMP4 was revealed by probemix P311 in the foetus. This finding was confirmed by probemix P424-B2 CHD associated loci (MRC, Holland). Investigation of the parental samples of DNA did not reveal any changes. The loss was considered to be pathogenic. The parents opted for termination of pregnancy at 21st week of pregnancy. The extent of the deletion
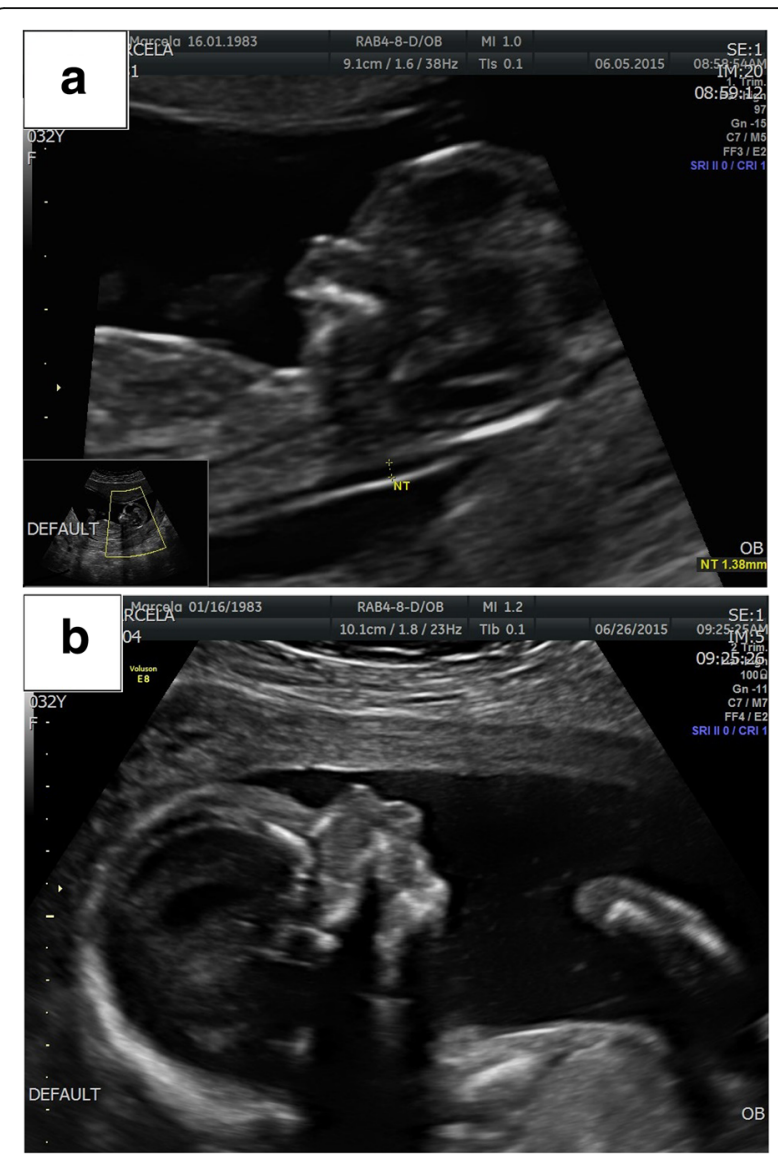

Fig. 1 a Atypical foetal face profile in the first trimester of pregnancy. b Micrognathia and hypoplasia of the nasal bone in the second trimester of pregnancy

was specified by microarray (Affymetrix Cytoscan HD, Santa Clara, USA) using DNA extracted from the sample of foetal skin biopsy after TOP. Array data were analysed using Chromosome analysis suite (CHAS) software (Affymetrix, Santa Clara, USA).

The result was as follows: $\operatorname{arr}[\mathrm{GRCh} 37]$ 14q22.1q23.1 [52468517_60202293] $\times 1$. The microdeletion spanned 7.7 $\mathrm{Mb}$ and involved 34 OMIM genes -9 morbid genes (Table 1). The detected chromosomal aberration was concluded as a cause of the clinical findings in the foetus and occurred de novo. Performed autopsy revealed besides of micrognathia and polydactyly, bilateral anophthalmia and horizontal palpebral fissure, lack of gyrification of the brain. Other organs were found to be without any morphological abnormality. Parental karyotypes were: $46, \mathrm{XX}$ and $46, \mathrm{XY}$.

\section{Discussion}

We report the microdeletion $14 \mathrm{q} 22 \mathrm{q} 23$ detected in the prenatal case as such an early detection has not been reported previously. As cases of prenatal detection of the microdeletion are scarce, the comparison 
Table 1 OMIM morbid genes included in the deleted region

\begin{tabular}{lll}
\hline Gene & $\begin{array}{l}\text { Gene } \\
\text { symbol }\end{array}$ & $\begin{array}{l}\text { OMIM } \\
\text { number }\end{array}$ \\
\hline prostaglandin D2 receptor & PTGDR & 604687 \\
prostaglandin E receptor 2 & PTGER2 & 176804 \\
DDHD domain containing 1 & DDHD1 & 614603 \\
bone morphogenetic protein 4 & BMP4 & 112262 \\
GTP cyclohydrolase 1 & GCH1 & 600225 \\
transmembrane protein 260 & TMEM260 & 617449 \\
orthodenticle homeobox 2 & OTX2 & 600037 \\
KIAA0586 & KIAA0586 & 610178 \\
dishevelled binding antagonist of beta & DACT1 & 607861 \\
catenin 1 & & \\
\hline
\end{tabular}

of the prenatally observed phenotype is limited. The relatively common features observed, however, in the few reported cases are orofacial malformations (micro -/rethrognathia, Pierre Robin sequence) which might be detected by US even in the first trimester of pregnancy as in our case $[1,2]$.

In contrast to the scarce detection of the microdeletion in the prenatal stages, the discovery of the interstitial microdeletion postnatally has been more frequently reported. There are several genes in the interval of deletion that are intolerant to the loss of function or are likely to exhibit haploinsufficency (DACT1, DDHD1, GCH1, BMP4, OTX2) based on the data in Decipher. The loss of heterozygosity in two of them (BMP4 and OTX2) is mostly consistent with the phenotype described in the patients. The hallmarks were ocular abnormalities [1-11] (Table 2). Absent or small orbits in the second trimester of gestation were seen $[3,7]$. Bilateral anophthalmia was discovered during autopsy in our case. Considerable variability in particular ocular defects and limitations of US make detection of the microdeletion in foetus difficult particularly in the early stages of pregnancy. Intragenic mutations in $B M P 4$ and OTX2 have been previously reported as having been causal for defects in ocular development [5, 8]. BMP4 is expressed in optic vesicle and optic cup, brain, teeth and digits [5]. Brain anomalies: dilatation of the lateral ventricles $[2,10]$, volume loss of white matter in the brain $[4,5]$, agenesis of the corpus callosum or thin corpus callosum $[4,5,7]$, hypoplasia or aplasia vermis $[5,8]$ were reported. Bilateral postaxial polydactyly of the hands $[2,9]$, syndactyly/polydactyly of the toes $[4,9,10]$ were associated with the finding microdeletion 14q22q23 apart from abnormalities of the digits - clinodactyly, brachydactyly $[1,3,4]$. Postaxial polydactyly and a lack of brain gyrification were confirmed in this case. Pituitary anomalies or hypogonadism/hypothyroidism were observed in several reports $[3-6,11]$. BMP4 expression is restricted to the diencephalic floor, which is consistent with the role in pituitary development [5]. Anomalies of the head were reported in the postnatal and prenatal cases $[3-5,7,11]$. Additional features associated with microdeletion involve micro-/retrognathia, maxillary hypoplasia, cleft uvula/palate, high arch palate or Pierre Robin sequence (PRS) [1-4, 8, 10-12] (Table 2). Micro-/retrognathia was seen during the US scan in the 17 th week of pregnancy and orofacial abnormality was even noticed in the first trimester ultrasound scan in our case when the PRS in the fetus was suspected. The Pierre Robin (PRS) sequence can be isolated or observed as a feature of a syndrome. An association with gene loci 2q24.1-33.3, 4q32-qter, 11q21-23.1, and 17q21-24.3 has been found [13]. Micrognathia, glosoptosis, and cleft palate characterize PRS. Micrognathia and cleft palate are detected in individuals with $B M P 4$ haploinsufficiency [2, 10-12] (Table 2). The role of BMP4 in otocephalyagnathia has been previously implicated [14]. BMP4 is expressed in the maxillary and mandibular processes [15]. Balanced BMP signalling and its local fineregulation is critical for organizing and maintaining craniofacial tissues and can be one of the cause of the PRS $[16,17]$. Referring to the role of BMP signalling in aetiology of PRS, one might also assume that the heterozygous loss of BMP4 might be an underlying cause of the PRS. The dosage changes, however, in expression of OTX2 also reveal the similar phenotype - mandibular, maxillary hypoplasia and retrognathia without ocular manifestation [18, 19] (Fig. 2). OTX2 encodes a transcription factor that plays a critical role in craniofacial development and anterior brain morphogenesis. Heterozygous loss-of-function studies in mice showed a range of severe craniofacial anomalies - micrognathia, agnathia, anophthalmia - in haploinsufficient mice [20]. Micrognathia and ear anomalies were also observed in SIX1 null murine mutants which indicate that SIX1 might be another candidate for orofacial defects in the deleted interval [21]. However, SIX1 was not involved in our detected deletion. It would seem that the contribution the genes of the region to the development of the mandible and ocular malformations might be more complex. It would be interesting to explore mutations in BMP4, OTX2 or SIX6 in patients with the isolated Pierre Robin sequence. The investigation has been focused on individuals with ocular manifestations thus far. BMP4 is also required for normal endocardial cushion expansion and remodelling. Loss of BMP4 in mice results in an insufficient number of cells in the developing outflow tract, endocardial cushions, defective cushion remodelling, ventricular septal defects, persistent truncus arteriosus, and abnormal semilunar valve formation [22]. Heart condition was reported only postnatally [9]. Some cases involving transposition of the great arteries, patent ductus arteriosus, and an atrioventricular canal defect 


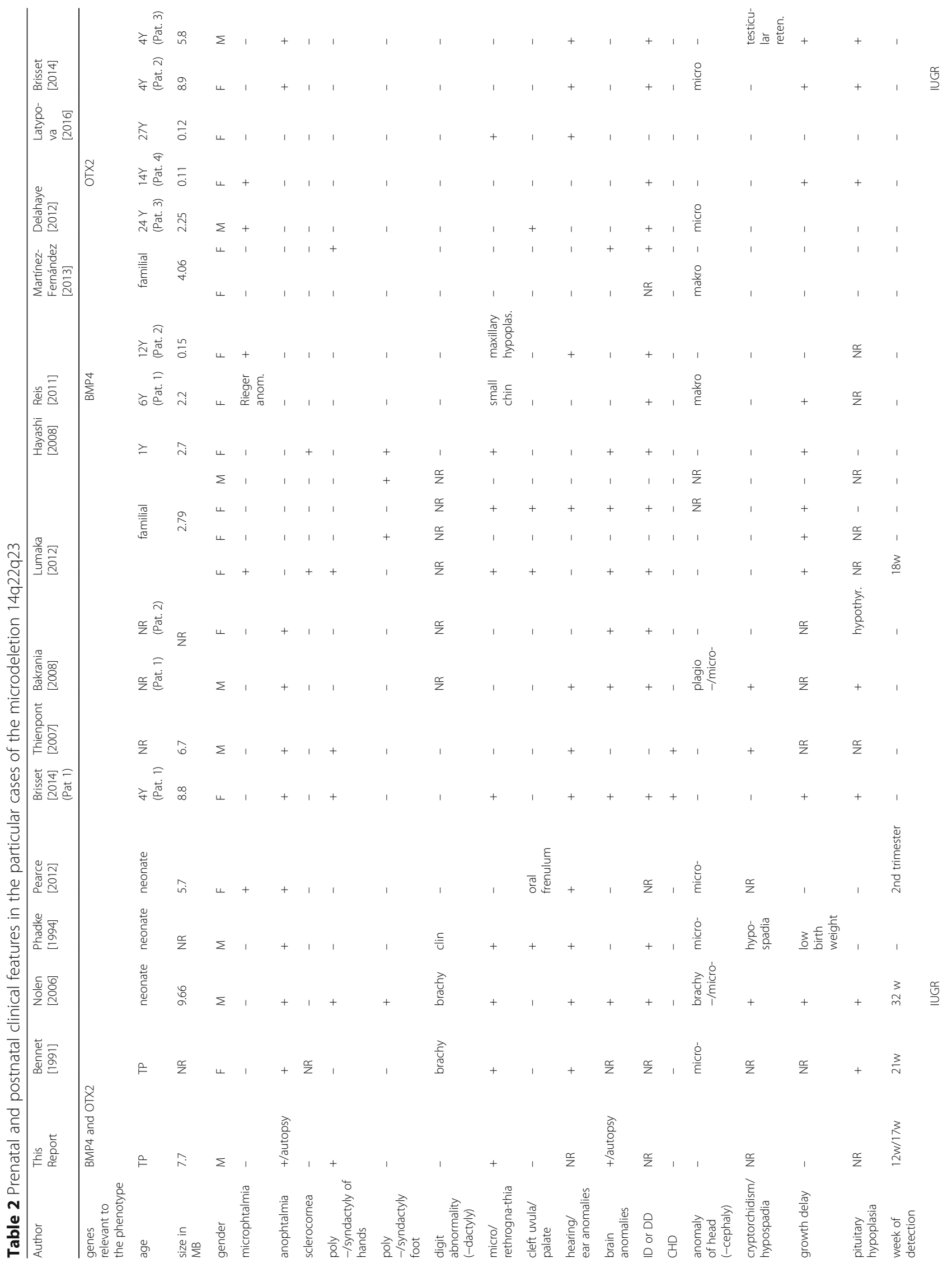




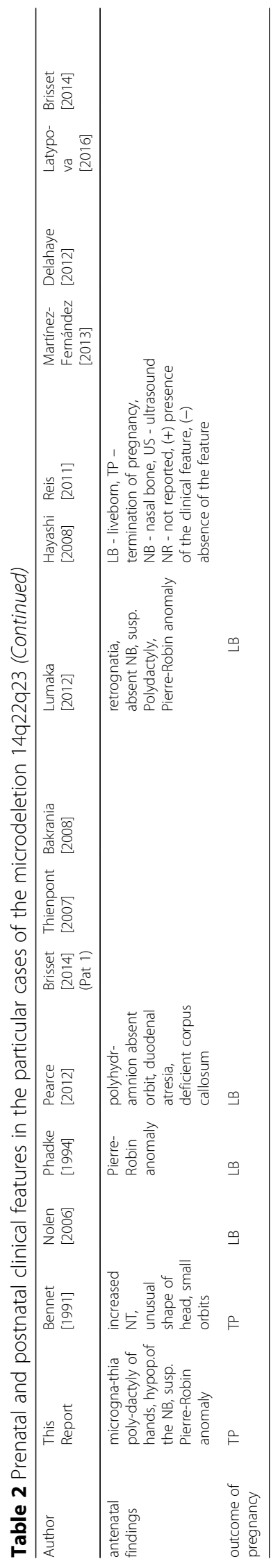




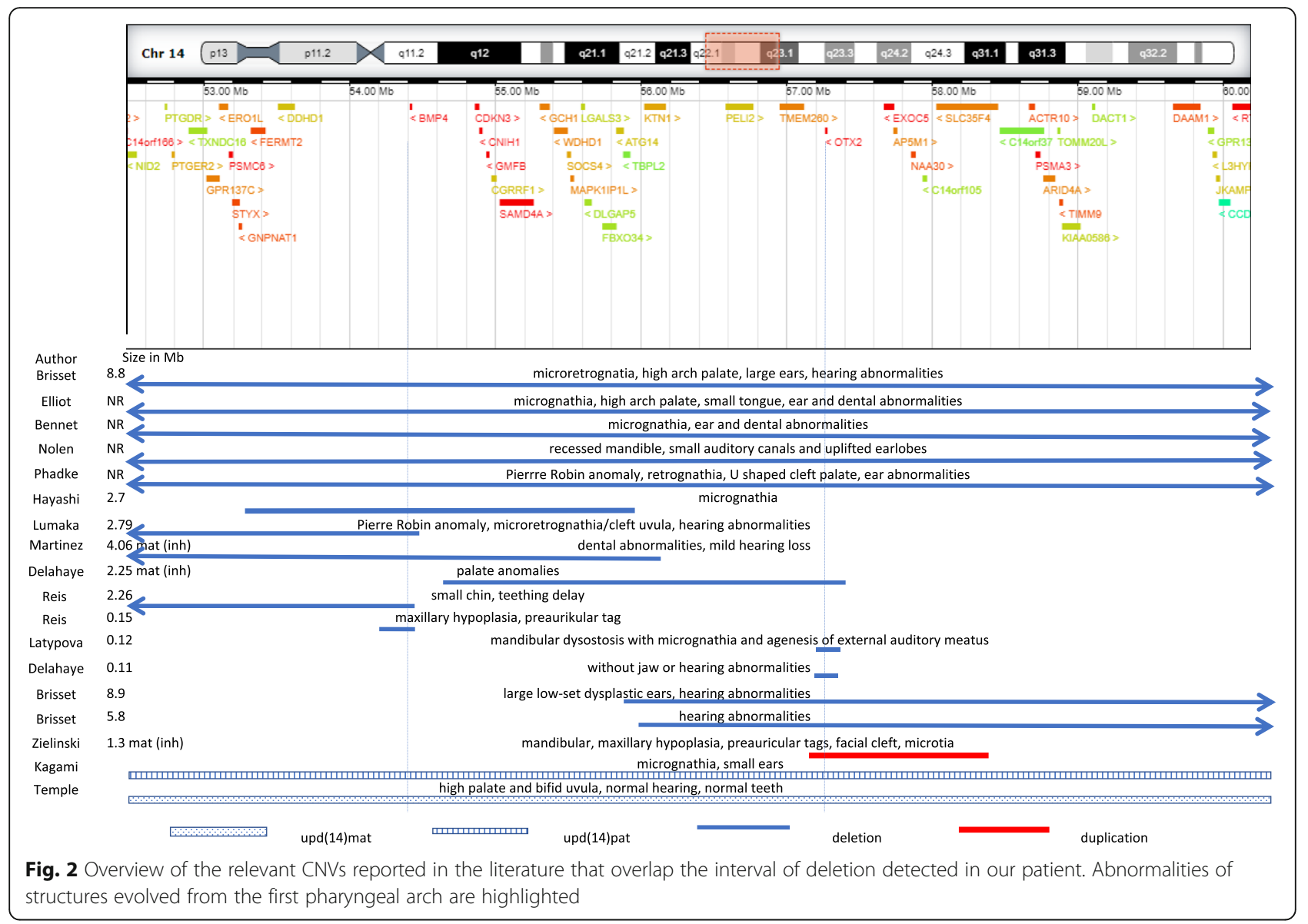

can be found in the Decipher database. However, no heart condition was noted during the autopsy in our case. Homozygous mutations in gene TMEM260, positioned approximately $2.5 \mathrm{Mb}$ from $B M P 4$, are associated with renal, cardiac malformations and agenesis of corpus callosum [23], the defects are also present in microdeletion $14 \mathrm{q} 22 \mathrm{q} 23$ or mutations in BMP4 [4, 5, 7-9]. Interestingly, kidney malformation and jaw and ear defects are hallmarks of Townes-Brock syndrome 1- TBS1 (\#107480) [24]. Recently, heterozygous mutation of DACT1 has been reported as a cause of TBS2 (\#617466) [25]. Hypospadia and ear abnormalities (microtia, overfolding of both ears), observed in patients with DACT1 mutation, have been involved in the phenotype of the patients with microdeletion/duplication 14q22q23 $[1,3,4,11,19]$. Abnormality of jaws has not been involved, however, in the phenotype.

Taken all together, deletions covering the interval between the genes BMP4 and SIX6 are associated with a typical phenotype with ocular, orofacial and brain malformations, growth delay, pituitary anomalies and poly-/syndactyly. Smaller deletions, involving either of the genes, are manifested with milder phenotypes. Deletions, involving BMP4 and adjacent genes without
OTX2, have been suggested recently as the cause of Frias syndrome - growth deficiency, exophtalmia, facial anomalies (cleft lip and palate, palpebral ptosis) and hand and foot alternations [26]. Moreover, deletions covering OTX2 are more frequently associated with microcephaly $[1,7,11,12]$ in comparison with the mutations restricted to $B M P 4$ where macrocephaly has predominantly been reported $[8,26]$. Extreme variability in phenotypes, either large or smaller deletions, indicates incomplete penetrance and the modifying effect of genetic background (interplay of other genes in different or common molecular pathways such as SHH, FGF8, etc) $[14,27]$. Little is known about the influence of the parental origin of the deletion on the resulting phenotype. It should be taken into account, however, as the upd (14) either paternal or maternal, causes recognizable syndromes. There are certain features which overlap with the phenotype of the microdeletion 14q22q23. Growth restriction, for example, in patients with upd (14) mat $[11,28]$, polyhydramnion in patients with upd (14) pat [7, 29] or orofacial malformations in both. Micrognathia, retrognathia or high arch palate are frequently described in patients either with upd (14) mat [28] or upd (14) pat [30-32]. Paternal isodisomy of 
chromosome 14 was described in patients with maxillary and mandibular hypoplasia [33]. Eggermann has reported the case of segmental upd (14) mat ranges from $14 \mathrm{q} 12$ to $14 \mathrm{q} 31$. The propositus revealed hypoplastic and retracted mandible, but no ocular, brain or other congenital malformations [34]. Moreover, there is some evidence that maternally inherited duplication of OTX2 manifested with hemifacial microsomia involving mandibular, maxillary hypoplasia and retrognathia [19]. It might indicate that equal biparental contribution of genes BMP4 or OTX2 is necessary for correct maxillary and mandibular development. Recently, the cluster of genes in interval 14q32.2, including paternally expressed genes DLK1 and RTL1 and maternally expressed genes MEG3 (GTL2), RTL1 (RTL1 antisense), MEG8, snoRNAs, and microRNAs, has been identified as responsible for imprinting disorders: Temple syndrome (\#616222) and Kagami - Ogata syndrome (\# 608149) [35]. It is not clear whether expression of further genes on chromosome 14 is influenced by imprinting.

\section{Conclusion}

We assume that the heterozygous loss of genes $B M P 4$ and OTX2 determines the major features detected in the foetus. Both genes are relevant in the development of craniofacial structures (especially structures evolved from the first pharyngeal arch). The phenotype of the microdeletion is highly variable even within families, which implies variable penetrance. If an atypical foetal face profile is found during the ultrasound scan in the first trimester of pregnancy, it can be a sign of rare chromosomal abnormalities. If the micro-/retrognathia or Pierre Robin sequence is observed during ultrasound scan in the second trimester of pregnancy, the presence of micro- or anophthalmia should be checked as a possible marker of microdeletion 14q22q23. The patient should consult the diagnosis with the clinical geneticist. Molecular karyotyping should be used in the cases. However, method MLPA might also provide the useful and cost-efficient alternative for detection of such an abnormality, where mandibular, ophthalmic or orofacial abnormalities are prenatally seen.

\section{Abbreviations}

CNV: Copy number variant; IUGR: Intrauterine growth retardation; MLPA: Multiplex ligation-dependent probe amplification; TOP: Termination of pregnancy

\section{Acknowledgments}

The authors would like to thank the prospective parents for their collaboration.

\section{Funding}

The whole study was supported by Ministry of Health of the Czech Republic, grant nr. DRO (FNOL 00098892).

\section{Availability of data and materials}

The datasets analysed during the current study are available from the corresponding author on reasonable request.

\section{Authors' contributions}

PC and IM wrote the manuscript; IM, AS and VD coordinated the clinical analysis of the patient; PC performed the cytogenetic analysis; AS performed MLPA analysis, KS performed microarray and JS signed microarray result. All authors read and approved the final manuscript.

\section{Ethics approval and consent to participate}

Study approval was obtained from the Institutional Review Board of the University Hospital and Faculty of Medicine and Dentistry Palacky University Olomouc. All procedures were conducted in accordance with the declaration of Helsinki.

\section{Consent for publication}

Written informed consent was obtained from the prospective parents for anonymous publication of the case.

\section{Competing interests}

All authors declared that they have no competing interests.

\section{Publisher's Note}

Springer Nature remains neutral with regard to jurisdictional claims in published maps and institutional affiliations.

\section{Author details}

'Department of Medical Genetics, University Hospital Olomouc, I.P.Pavlova 6, Olomouc, Czech Republic. ${ }^{2}$ Department of Obstetrics and Gynaecology, University Hospital Olomouc, Olomouc, Czech Republic. ${ }^{3}$ Institute of Molecular and Translational Medicine, Faculty of Medicine and Dentistry, Palacky University Olomouc, Olomouc, Czech Republic.

Received: 6 November 2017 Accepted: 18 December 2017 Published online: 28 December 2017

\section{References}

1. Phadke RS, Sharma AK, Agarwal SS. Anophtalmia with cleft palate and micrognathia: a new syndrome? J Med Genet. 1994;31:960-1.

2. Lumaka A, Van Hole C, Casteels I, Ortibus E, De Wolf V, Vermeesch JR, et al. Variability in expression of a familial $2.79 \mathrm{Mb}$ microdeletion in chromosome 14q22.1-22.2. Am J Med Genet. 2012;158A(6):1381-7.

3. Bennet CP, Betts DR, Seller MJ. Deletion 14q(q22q23) associated with anophthalmia, absent pituitary, and other abnormalities. J Med Genet. 1991; 28:280-1.

4. Nolen LD, Amor D, Haywood A, St. Heaps L, Ch W, Mihelec M, et al. Deletion at 14q22-23 indicates a contiguous gene syndrome comprising anophthalmia, pituitary hypoplasia, and ear anomalies. Am J Med Genet. 2016;140A:1711-8.

5. Bakrania P, Efthymiou M, Klein JC, Salt A, Bunyan DJ, Wyatt A, et al. Mutations in BMP4 cause eye, brain, and digit developmental anomalies: overlap between the BMP4 and hedgehog signaling pathways. Am J Hum Genet. 2008;82:304-19.

6. Elliott J, Maltby EL, Reynolds B. A case of deletion 14q (q22.1->q22.3) associated with anophthalmia and pituitary abnormalities. J Med Genet. 1993;30:251-2.

7. Pearce ZD, Droste PJ, Aeberg TM Jr, Hassan AS. Ophtalmic and systemic findings in interstitial deletions of chromosome 14q: a case report and literature review. Ophthalm Genet. 2012;33(3):161-6.

8. Reis LM, Tyler RC, Schilter KF, Abdul-Rahman O, Innis JW, Kozel BA, et al. BMP4 loss-of-function mutations in developmental eye disorders including SHORT syndrom. Hum Genet. 2011;130:495-504.

9. Thienpont B, Mertens L, de Ravel T, Eyskens B, Boshoff D, Maas N, et al. Submicroscopic chromosomal imbalances detected by array -CGH are a frequent cause of congenital heart defects in selected patiens. Eur Heart J. 2007;28:2778-84.

10. Hayashi S, Imoto I, Inazawa J, Okamoto N, Makita Y, Hata A. Heterozygous deletion at 14q22.1-q22.3 including the BMP4 gene in a patient with psychomotor retardation, congenital corneal opacity and feet polysyndactyly. Am J Med Genet. 2008;146A:2905-10. 
11. Brisset S, Slamova S, Dusatkova P, Briand-Suleau A, Milcent K, Metay C, et al. Anophthalmia, hearing loss, abnormal pituitary development and response to growth hormone therapy in three children with microdeletions of 14q22q23. Mol Cytogenet. 2014;7:17.

12. Delahaye A, Bitoun P, Drunat S, Gérard-Blanluet M, Chassaing N, Toutain $A$, et al. Genomic imbalances detected by array-CGH in patients with syndromal ocular developmental anomalies. Eur J Hum Genet. 2012;20: 527-33.

13. Jakobsen LP, Knudsen MA, Lespinasse J, García Ayuso C, Ramos C, Fryns JP, et al. The genetic basis of the Pierre Robin sequence. Cleft Palate Craniofac J. 2006;43:155-9.

14. Schmotzer $\mathrm{CL}$, Shehata BM. Two cases of agnathia (otocephaly): with review of the role of fibroblast growth factor (FGF8) and bone morphogenetic protein (BMP4) in patterning of the first branchial arch. Pediatr Dev Pathol. 2008:11:321-4.

15. Bennett $\mathrm{JH}$, Hunt $\mathrm{P}$, Thorogood $\mathrm{P}$. Bone morphogenetic protein-2 and -4 expression during murine orofacial development. Arch Oral Biol. 1995;40: 847-54.

16. Graf D, Malik Z, Hayano S, Mishina Y. Mini review: common mechanisms in development and disease. Cytokine Growth Factor Rev. 2016;27:129-39.

17. Yang $Y$, Yuan J, Yao X, Zhang $R$, Yang $H$, Zhao $R$, et al. BMPR1B mutation causes Pierre Robin sequence. Oncotarget. 2017:8:25864-71.

18. Latypova X, Bordereau S, Bleriot A, Pichon O, Poulain D, Briand A, et al. Mandibular dysostosis without microphthalmia caused by OTX2 deletion. Am J Med Genet. 2016;170A:2466-70.

19. Zielinski D, Markus B, Sheikh M, Gymrek M, Chu C, Zaks M, et al. OTX2 duplication is implicated in hemifacial microsomia. PLoS One. 2014;9: e96788.

20. Matsuo I, Kuratani S, Kimura C, Takeda N, Aizawa S. Mouse Otx2 functions in the formation and patterning of rostral head. Genes Dev. 1995;9:2646-58.

21. Laclef C, Hamard G, Demignon J, Souil E, Houbron C, Maire P. Altered myogenesis in Six1-deficient mice. Development (Cambridge, England). 2003;130:2239-52.

22. McCulley DJ, Kang JO, Martin JF, Black BL. BMP4 is required in the anterior heart field and its derivatives for endocardial cushion remodelling, outflow tract septation, and semilunar valve development. Dev Dyn. 2008;237:320032009.

23. Ta-Shma A, Khan TN, Vivante A, Willer JR, Matak P, Jalas C. Mutations in TMEM260 cause a pediatric neurodevelopmental, cardiac, and renal syndrome. Am J Hum Genet. 2017;100:666-75.

24. Keegan CE, Mulliken JB, BL W. Korf Br: Townes-Brock syndrome versus expanded spektrum hemifacial microsomia: review of eight patiens and further evidence of a "hot spot" for mutations in SALL1 gene. Genet Med. 2001:3:310-3.

25. Webb BD, Metikala S, Wheeler PG, Sherpa MD, Houten SM, Horb ME, et al. Heterozygous pathogenic variant in DACT1 causes an autosomal-dominant syndrome with features overlapping Townes-brocks syndrome. Hum Mutat. 2017;38:373-7.

26. Martinez-Fernandez ML, Bermejo-Sanchez E, Fernandez B, MacDonald A, Fernandez-Toral J, Martinez-Frias ML. Haploinsufficiency of BMP4 gene may be the underlying cause of Frias syndrome. Am J Med Genet. 2014;164A: 338-45

27. Liu W, Selever J, Murali D, Sun X, Brugger SM, Ma L, et al. Threshold-specific requirements for Bmp4 in mandibular development. Dev Biol. 2005;283: 282-93.

28. Temple IK, Cockwell A, Hossold T, Pettay D, Jacobs P. Maternal uniparental disomy for chromosome 14. J Med Genet. 1991;28:511-4.

29. Kagami M, Kato F, Matsubara K, Sato T, Nishimura G, Ogata T. Relative frequency of underlying genetic causes for the development of UPD (14) pat-like phenotype. Eur J Hum Genet. 2012;20:928-32.

30. Kagami M, Kurosawa K, Miyazaki O, Ishino F, Matsuoka K, Ogata T. Comprehensive clinical studies in 34 patients with molecularly defined UPD (14) pat and related conditions (Kagami-Ogata syndrome). Eur J Hum Genet. 2015:23:488-98

31. Hosoki K, Kagami M, Tanaka T, Kubota M, Kurosawa K, Kato M, et al. Original article: maternal Uniparental Disomy 14 syndrome demonstrates Prader-Willi syndrome-like phenotype. J Pediat. 2009;155:900-3.

32. Watanabe T, Shun Y, Yasuhisa N, Keiya F, Hayato G, Masayo K. Prenatal findings and epimutations for paternal uniparental disomy for chromosome 14 syndrome. J Obstet Gynaecol Res. 2015:41:1133-6.
33. Matthew E. Paternal uniparental isodisomy for chromosome 14 with mosaicism for a supernumerary marker chromosome 14. J Med Genet. 2007; 143A:2165-71.

34. Eggermann T. Identification of interstitial maternal uniparental disomy (UPD) (14) and complete maternal UPD (20) in a cohort of growth retarded patients. J Med Genet. 2001;38:86-9.

35. Ogata T, Kagami M. Kagami-Ogata syndrome: a clinically recognizable upd (14) pat and related disorder affecting the chromosome 14q32.2 imprinted region. J Hum Genet. 2016;61:87-94. Decipher. https://decipher.sanger.ac. uk. Accessed 1 Dec 2017

\section{Submit your next manuscript to BioMed Central and we will help you at every step:}

- We accept pre-submission inquiries

- Our selector tool helps you to find the most relevant journal

- We provide round the clock customer support

- Convenient online submission

- Thorough peer review

- Inclusion in PubMed and all major indexing services

- Maximum visibility for your research

Submit your manuscript at www.biomedcentral.com/submit 